\title{
Radiographic Evaluation of Five Variables in Iraqi Young Subjects among Impacted and Erupted Lower Wisdom Teeth Groups
}

\author{
Nuhad A. Hassan ${ }^{1}$, Amal R.S. Mohammed ${ }^{2}$ \\ ${ }^{I}$ M.Sc., Assistant Professor at Department of Oral Medicine, College of Dentistry, AL-Mustansiriyah University, \\ Iraq, ${ }^{2}$ M.Sc., Professor at Department of Oral Medicine, College of Dentistry, AL-Mustansiriyah University, Iraq
}

\begin{abstract}
Objective: To look at those contrasts in five variables in connection to sex between impacted and erupted lower wisdom teeth groups on digital panoramic radiographs in Iraqi young subjects.

Those variables that compared were: retromolar space might have been measured by drawing a line starting with Ricketts (Xi) by drawing accordance with the focal point of the ramus on the distal surface of the lower 2nd molar. Retromolar space starting from the anterior edge of claiming ramus (AER-7) might have been measured dependent upon those distal surfaces of the more level the 2nd molar along the occlusal plane. The angle of the tooth axis of the 2 nd and 3rd molar ( $\beta$ angle). Mesiodistal width of the lower wisdom tooth (MDW) was calculated, while space/width ratio (SWR) might have been gotten through (AER-7/MDW).
\end{abstract}

Materials and Method: This study comprised 80 patients their ages varying between 20 and 25 years all of them having full dentition with bilaterally present mandibular 3rd molars. After they examine clinically, lower 3rd molars were distributed into two; Group A erupted (20 male and 20 female), whereas Group B included the impacted mandibular 3rd molars (20 male and 20 female). Five variables were measured in all radiographs to make a comparison between the two groups. The data analysis was done by using SPSS (ver.10) by applying T-test and descriptive tests.

Results: The means of (Xi-7, AER-7, MDW) are larger in males than females in both groups A and B. The means of (Xi-7, AER-7,) are larger in group A than group B. the mean of the $\beta$ angle is larger in group B. the mean of SWR in group B is less than1.

Conclusion: This study demonstrated that the long axes of the 2 nd molar and wisdom teeth ( $\beta$ angle) and a space parameter were important parameters in predicting mandibular 3rd molar eruption.

Keywords: Panoramic; 3rd molar; impacted tooth, ramus, center.

\section{Introduction}

The 3rd molar (M3) varies more than the opposite molars in terms of shape, size, the timing of eruption,

\author{
Corresponding Author: \\ Nuhad A. Hassan \\ Department of Oral Medicine/College of Dentistry/Al- \\ Mustansiriyah University \\ Phone Number: 964+07803327473 \\ e-mail: alwanxray@gmail.com
}

and even tendency toward the impaction. In modern societies, M3s get impacted for more than any other teeth, and the impaction of mandibular M3 is more common than its maxillary counterpart ${ }^{1}$. Impaction can be defined as the failure of the whole eruption right into an everyday useful function of one tooth within ordinary time due to the absence of space within the dental arch, as a result of obstruction with some other tooth or development in an abnormal position ${ }^{2}$. Panoramic radiography is a radiological technique thatcan produce a single tomographic X-ray image of curved facial structures, including the maxillary and mandibular 
dental arches together with their supporting structures. Based on panoramic radiograms, it is possible to evaluate developing wisdom teeth and their surrounding tissues ${ }^{3}$. As stated by a few studies, there is no sex predilection in the impaction of $\mathrm{M}^{4,5}$. However, Hugoson and Kugelberg ${ }^{6}$ indicated a higher frequency in females than males.

The point of this investigation to look at those contrasts in five variables in connection to sex between erupted and impacted lower wisdom teeth groups on digital panoramic radiographs in Iraqi young subjects.

\section{Materials and Method}

In this study, the samples collected retrospectively from the patients attending the college of dentistryMustansiriyah University from the time between (September 2017 - April 2018), about 80 patients all of them having full dentition with bilaterally present mandibular wisdom teeth their ages are among 20 and 25 years ( 40 were females and 40 were males). Patients were divided into two groups of mandibular wisdom teeth, first group was A, the patients in group A were having mandibular wisdom teeth which were fully erupted into functional position in the other side there was the 2nd group B, the patients in group B comprised the mandibular wisdom teeth which were below the occlusal plane/erupted up to the occlusal plane but they were not fully functional due to their aberrant angulations. Digital panoramic radiographs (My ray CE 0051(V.B1 cocc A 14/C-IMOLA (BO)-Italy, X-ray source $(75 \mathrm{kVp}, 5 \mathrm{~mA})$, exposure time $(9.34 \mathrm{sec})$, (52 $\mathrm{mGycm}$ ), the analyzing process for all patients was by using different measurements. The measuring of the retromolar area done with the aid of sketching a straight line starts from Ricketts (Xi) point i.e. centers of ramus and it reaches until the distal surface of the lower second molar. The retromolar area from the anterior edge of the ramus (AER-7) was measured up to the distal surface of the lower 2nd molar alongside the occlusal plane. The angle of the tooth axis of 2nd molar and wisdom tooth ( $\beta$ angle). The mesiodistal width of the lower wisdom tooth (MDW) was calculated; Figure (1), whereas the gap/width ratio (SWR) was obtained through (AER-7/ MDW). The means of all five variables between left and right have been taken. Data, which was then, analyzed the usage of SPSS for detecting the distinction between the two groups' means.

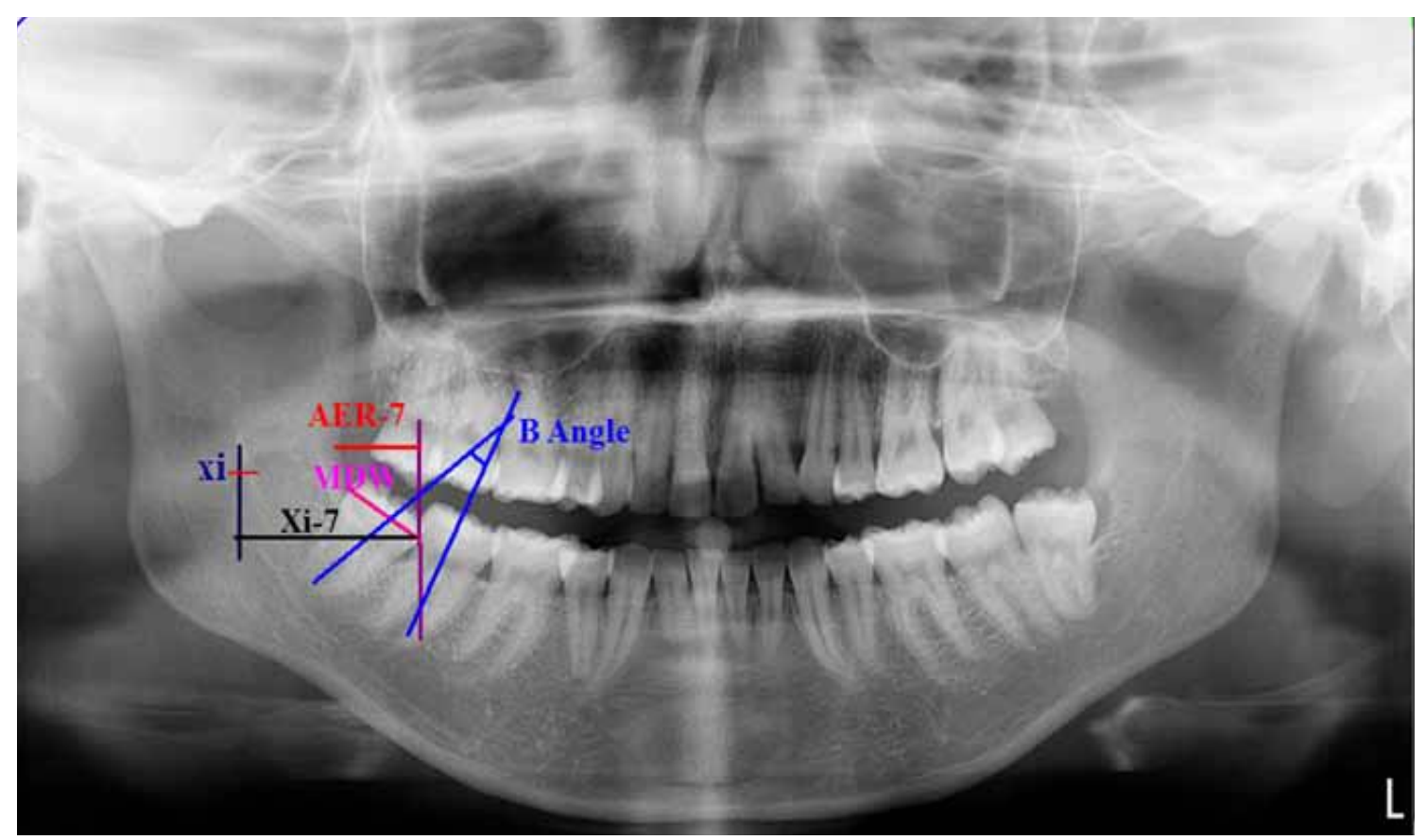

Figure (1): The measuring of the retromolar area was accomplished through sketching a straight line starts from Ricketts Xi point i.e. center of ramus and it attains till the distal surface of the lower 2 nd molar. The retromolar area from the anterior fringe of the ramus (AER-7) became measured as much as the distal surface of the lower 2 nd molar along the occlusal plane. The angle of the tooth axis of the 2 nd and 3 rd molar ( $\beta$ angle). Mesiodistal width of the lower 3rd molar (MDW). 


\section{Results}

The means of (Xi-7, AER-7, MDW, $\beta$ angle) would bigger for males than females in group A and the means of (Xi-7, AER-7, MDW) would bigger for males than females of group B, as shown in table (1).

Table (1): Descriptive of groups by gender.

\begin{tabular}{|l|l|l|c|c|c|c|c|}
\hline & Gender & Statistic & Xi-7 & AER-7 & MDW & $\boldsymbol{\beta}$ Angle & SWR \\
\hline \multirow{5}{*}{ Group A } & \multirow{3}{*}{ Female } & Mean & 28.415 & 16.7965 & 12.095 & 16.775 & 1.41115 \\
\cline { 2 - 8 } & & SD & 4.163185 & 1.477314 & 1.888955 & 3.097006 & 0.183264 \\
\cline { 2 - 8 } & \multirow{3}{*}{ Male } & Mean & 29.984 & 17.7045 & 13.343 & 16.925 & 1.35045 \\
\cline { 3 - 8 } & & SD & 3.988505 & 1.645637 & 2.288056 & 3.138366 & 0.170794 \\
\hline \multirow{3}{*}{ Group B } & \multirow{3}{*}{ Female } & Mean & 26.865 & 10.975 & 12.903 & 36.95 & 0.8477 \\
\cline { 3 - 8 } & & SD & 5.723477 & 3.70048 & 2.275161 & 3.594221 & 0.220419 \\
\cline { 3 - 8 } & \multirow{3}{*}{ Male } & Mean & 27.91 & 12.855 & 13.5135 & 36.475 & 0.94525 \\
\cline { 3 - 8 } & & SD & 6.006304 & 3.169837 & 2.278772 & 3.94193 & 0.124564 \\
\hline
\end{tabular}

In group A, the means of (Xi-7, AER-7) are larger than group B, the mean of SWR in group B is less than 1 while the mean of $\beta$ angle is larger in group $B$, table (2), figure (2) illustrated that.

Table (2): Descriptive of group A, and Group B.

\begin{tabular}{|c|c|c|c|c|c|c|}
\hline Groups & Statistic & $\mathrm{Xi}-7$ & AER-7 & MDW & $\beta$ Angle & SWR \\
\hline \multirow{2}{*}{ Group A } & Mean & 29.1995 & 17.2505 & 12.719 & 16.85 & 1.3815 \\
\hline & SD & 4.101854 & 1.610587 & 2.165219 & 3.078461 & 0.177685 \\
\hline \multirow{2}{*}{ Group B } & Mean & 27.3875 & 11.915 & 13.20825 & 36.7125 & 0.8965 \\
\hline & SD & 5.81502 & 3.531655 & 2.268746 & 3.731171 & 0.183451 \\
\hline
\end{tabular}

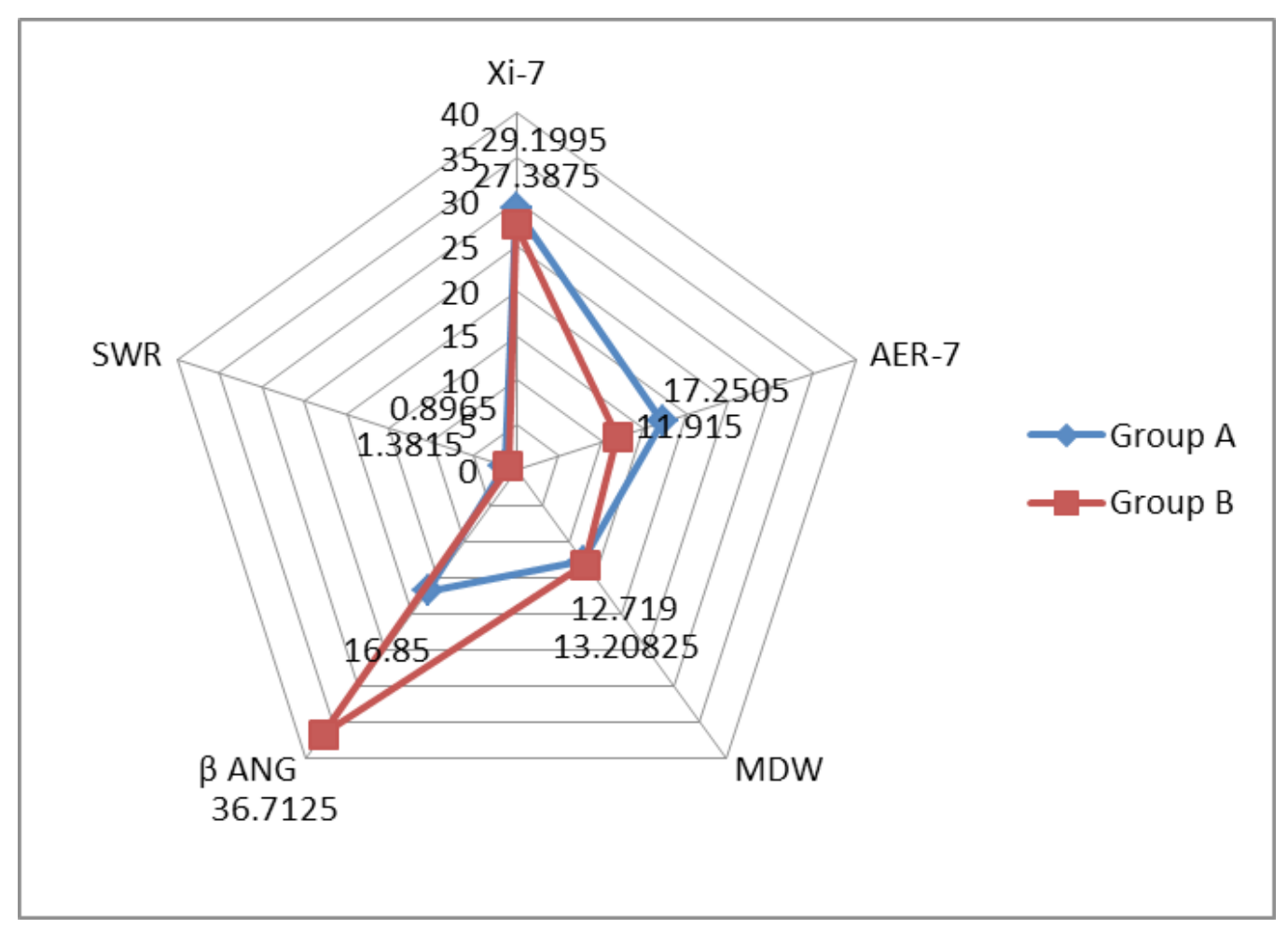


The T-test between males and females for (AER-7, MDW) indicated a statistically significant difference in group A while it indicated a statistically significant difference for (AER-7, MDW, SWR) in group B, table (3) explained that.

Table (3): T-test between Males and Females of each group.

\begin{tabular}{|l|l|c|c|c|c|c|}
\hline Groups & Statistic & Xi-7 & AER-7 & MDW & $\boldsymbol{\beta}$ Angle & SWR \\
\hline \multirow{3}{*}{ Group A } & t-test & 1.471 & 2.355 & 2.381 & 0.286 & 1.100 \\
\cline { 2 - 7 } & P-value & 0.158 & 0.029 & 0.028 & 0.778 & 0.285 \\
\hline \multirow{2}{*}{ Group B } & t-test & 1.090 & 3.889 & 2.517 & 0.414 & 2.515 \\
\cline { 2 - 7 } & P-value & $0.290 * * *$ & $0.001 * *$ & $0.021 *$ & $0.683 * * *$ & $0.021 *$ \\
\hline
\end{tabular}

The T-test between group A and group B showed a highly statistically significant difference for (AER-7, SWR, $\beta$ angle), table (4) clarified that.

Table (4): T-test between group A and group B.

\begin{tabular}{|l|c|c|c|c|c|}
\hline Statistic & Xi-7 & AER-7 & MDW & 及 Angle & SWR \\
\hline T-test & 2.201 & 12.260 & 1.472 & 22.433 & 10.178 \\
\hline P-value & $0.034^{*}$ & $\mathrm{P}<0.01 * *$ & $0.149 * * *$ & $\mathrm{P}<0.01 * *$ & $\mathrm{P}<0.01 * *$ \\
\hline
\end{tabular}

$* \mathrm{P}<0.05$ Significant, $* * \mathrm{P}<0.01$ High significant, $* * * \mathrm{P}>0.05$ Non-significant

\section{Discussion}

Due to there is no space in human jaws, this thing has been a subject of great interest for a long period. The mandibular retromolar space is one of the most studied factors for two main reasons: the lower wisdom teeth are the 2 nd most-affected teeth ${ }^{7,8,9}$ and the absence of space may be viewed as the main reason for this. Thus, the tests of this space must be performed very carefully, particularly on young patients ${ }^{10}$. It'd make expected that facial growth, jaw size, and tooth length differ amongst races and populations seeing that there were only a few studies articles around this problem primarily based on the Serbian population ${ }^{11}$, this observes comparative in terms of gender for the Iraqi full dentition population, it showed that $\beta$ perspective and an area parameter had been valuable parameters in predicting mandibular $3 \mathrm{rd}$ molar eruption which is in a near settlement with the part of findings of a examine performed with the aid of Uthman $(2007)^{12}$ using panoramic radiographs for Iraqi subjects.

Within the present day observe, the mean value for xi-7 became larger for Group A than for the organization on Group B which turned into near findings through others ${ }^{13,14}$ and it concluded that the average value for xi-7 turned into larger in adult males than ladies with a full eruption that's in the settlement with some other previous examine ${ }^{15}$.In this study, the suggested distance from AER to the distal surface of the 2nd molar becomes larger for A than Group B. tremendous difference turned into found among the two clusters. Ventä ${ }^{16}$ stated that the probability of eruption is $100 \%$ if the retromolar area is as a minimum of $16.5 \mathrm{~mm}$ and Quiros and Palma ${ }^{17}$ additionally located the range between $14-17 \mathrm{~mm}$ in the erupted group that is an agreement with the result of this look at. The prevailing examination conforms with the finding of Hattab and Alhaija ${ }^{18}$ who mentioned that ladies had smaller than males. The prevailing have a look at and different research ${ }^{14,18}$ additionally affirmed that 3rd molars had been larger in the impacted group. It'd had been viewed as that the growth of the lower retromolar area ought not to be anticipated after the age of $16^{19,20}$. On the other hand, Chen et al. ${ }^{21}$ observed that there is a sizeable growth of this area between the age of sixteen and eighteen. this problem may be clinically considerable, considering that possibility to predict impaction of lower 3rd molar in an early stage could favor the decision to get rid of it easily earlier than the roots are completely shaped .within this survey at the SWR become bigger within the erupted group with the average value of 1.3815 wherein as within the impacted group, it changed into 0.8965 . 
That is following preceding studies ${ }^{12}$ which found this ratio to be much less than 1 within the marginal eruption group and greater than 1 in the total eruption group. Olive and Basford ${ }^{22}$ concluded that the gap/ width ratio gives a dependable appraisal of the available retromolar space for the 3rd molar eruption and that orthopantomogram presents for the best estimation of the desired ratio, whilst the lateral cephalogram is unsure. Kahl et al. ${ }^{23}$ located that the general public $(97.40 \%)$ of impacted teeth did no longer have enough space and after 7 years of the statement, Gansset al. ${ }^{24}$ concluded that, if the gap/3rd molar width ratio is greater than 1 , most of the wisdom teeth could ultimately enter the arch which confirmed with the locating of this research.

An Iranian study executed via Ezoddini Ardakaniet, et al. in $2014^{25}$ to determine and evaluate the eruption space of unerupted and erupted 3rd molars via the approach of digital panoramic radiography (seventythree men and seventy-seven ladies with the common age of $21.18 \pm 1.67$ years), a statistically giant difference was located among the 2 groups in regard with the common perspective among 2 nd and $3 \mathrm{rd}$ molar, the implied space of retro-molar and its ratio to the width of 3rd molar in addition to the suggest distance among centers of ramus and 2 nd molar $(\mathrm{P}=0.0001)$, they concluded that increasing the angle among 2 nd and 3rd molar, as well as an inadequate area of retro-molar, can cause impaction of lower 3rd molar that is in a close settlement with the effects of this Iraqi examine.

In the current study, the $\beta$ perspective is larger in group $\mathrm{b}$ and women than group $\mathrm{A}$ and males, so it has been validated that the larger the inclination, the larger the probability of impaction which is in similarity with the result of the previous study ${ }^{26}$. It has been recommended in other to examine that if a 3rd molar has a low preliminary inclination and good enough area, then eruption is viable ${ }^{3}$.

\section{Conclusion}

This study demonstrated that the long axes of the 2nd and 3rd molars ( $\beta$ angle) and a space parameter were important parameters in predicting mandibular $3 \mathrm{rd}$ molar eruption.

Ethical Statement: This study was conducted in accordance with the World Medical Association. Declaration of Helsinki, the approval of the scientific committee of the Oral Medicine Department was gotten.

Declaration of Competing Interest: The authors declare that they have no known competing financial interests or personal relationships that could have appeared to influence the work reported in this paper.

Funding: No funding was received for this study.

\section{References}

1. Abu Alhaija ES, AlBhairan HM,AlKhateeb SN. Mandibular third molar space in different anteroposterior skeletal patterns. Eur J Orthod 2011; 33: 570-6.

2. Khawaja NA. Third molar impaction: a review. J Pak Dent Assoc 2006; 15:97-101.

3. Hattab FN. Positional changes and eruption of impacted mandibular third molars in young adults. Aradiographic 4-year follow-up study. Oral Surg Oral Med Oral Pathol Radiol Endod, 1997; 84: 604-608.

4. Hattab FN, Rawashdeh MA, Fahmy MS. Impaction status of third molars in Jordanian students.Oral Surg Oral Med Oral Pathol Oral Radiol Endod 1995; 79: 24-9.

5. Breik $\mathrm{O}$ and Grubor D. The incidence of mandibular third molar impactions in different skeletal face types. Aust Dent J 2008;53: 320-4.

6. Hugoson A and Kugelberg CF. The prevalence of third molars in a Swedish population. An epidemiological study. Community Dent Health 1988; 5: 121-38.

7. Bishara SE and Anreasen G. Third Molars: a review. Am J Orthod 1983; 83(2): 131-7.

8. Dachi SF and Howell FV. A survey of 3, 874 routine full-month radiographs. II. A study of impacted teeth. Oral Surg Oral Med Oral Pathol 1961; 14: 1165-9.

9. Grover PS and Lorton L. The incidence of unerupted permanent teeth and related clinical cases. Oral Surg Oral Med Oral Pathol 1985; 59(4): 420-5.

10. Zelić K and Nedeljković N. Size of the lower third molar space in relation to age in Serbian Population. Vojnosanit Pregl 2013; 70(10): 923-928.

11. Nedeljkovic N, Stamenkovic Z, Tatic Z, Racic A. Possibilty of the lower third molar eruptionradiographic analysis. Vojnosanit Pregl 2006; 63(2): 159-62. (Serbian).

12. Uthman A. Retromolar space analysis in relation to selected linear and angular measurements for 
an Iraqi sample. Oral Surgery, Oral Medicine, Oral Pathology, Oral Radiology, and Endodontics 2007;104: e76-e82.

13. Schulhof RJ. Third molars and orthodontic diagnosis. J Clin Orthod 1976; 10:272-81.

14. Qamruddin I, Qayyum W, Haider SM, Siddiqui SW, Rehan F. Differences in various measurements on panoramic radiograph among erupted and impacted lower third molar groups.J Pak Med Assoc 2012;62 (9): 883-887.

15. Ventä I, Murtomaa H, Turtola L, Meurman J, Ylipaavalniemi P. Assessing the eruption of lower third molars on the basis of radiographic features. Br J Oral Maxillofac Surg 1991; 29: 259-62.

16. Ventä I, Murtomaa H, Ylipaavalniemi P.A device to predict lower third molar eruption. Oral Surg Oral Med Oral Pathol Oral Radiol Endod 1997; 84: 598-603.

17. Quiros $\mathrm{O}$ and Palma A. The mandibular third molar. A method of predicting its eruption. The Orthodontic Cyber Journal. (Online) (Cited 1999 July 20).Available from URL: http://www.oc-j. com/3rdmolar/3rdmlr.html.

18. Hattab FN and Alhaija ES. Radiographic evaluation of mandibular third molar eruption space.Oral Surg Oral Med Oral Pathol Oral Radiol Endod 1999; 88:285-91.

19. Niedzielska IA, Drugacz J, Kus N, Kreska J. Panoramic radiographic predictors of mandibular third molar eruption. Oral Surg Oral Med Oral
Pathol Oral Radiol Endod 2006; 102(2):154-8; discussion 159.

20. Ledyard BC Jr. A study of the mandibular third molar area. Am J Orthod 1953; 39: 366-9.

21. Chen LL, Xu TM, Jiang JH, Zhang XZ, Lin JX. Longitudinal changes in mandibular arch posterior space in adolescents with normal occlusion. Am J OrthodDentofacOrthop 2010; 137(2): 187-93.

22. Olive $\mathrm{R}$ and Basford $\mathrm{K}$. Reliability and validity of lower third molar space- assessment techniques. Am J Orthod 1981; 79(1):45-53.

23. Kahl B, Gerlach KL,Hilgers RD. A long-term, follow-up, radiographic evaluation of asymptomatic impacted third molars in orthodontically treated patients. Int J Oral Maxillofac Surg1994; 23(5): 279-85.

24. Ganss C, Hochban W, Keilbassa AM., Umstad HE. Prognosis of third molar eruptrion Oral Surg Oral Med Oral Pathol Oral RadiolEndod 1993; 76(6): 688-93.

25. EzoddiniArdakani F, Mirbeigi S, Jebali H, Besharati S. Comparing eruption space of the lower third molar in unerupted and erupted teeth via digital panoramic radiography in patients referring to yazd dental college during 2011-2013. J Shahid Sadoughi Univ Med Sci 2014; 22(3): 1246-55.

26. Shiller WR. Positional changes in mesio-angular impacted mandibular third molars during a year. $\mathrm{J}$ Am Dent Assoc 1979; 99: 460-4. 